\title{
Capture Myopathy in Little Bustards after Trapping and Marking
}

\author{
Ignasi Marco, ${ }^{1,4}$ Gregorio Mentaberre, ${ }^{1}$ Anna Ponjoan, ${ }^{2}$ Gerard Bota, ${ }^{2}$ Santi Mañosa, ${ }^{3}$ and Santiago Lavín ${ }^{1}$ \\ 1 Servei d'Ecopatologia de Fauna Salvatge, Facultat de Veterinaria, Universitat Autonoma de Barcelona, 08193- \\ Bellaterra, Spain; ${ }^{2}$ Àrea de Biodiversitat, Centre Tecnològic Forestal de Catalunya, Pujada del Seminari, s/n, \\ 25280-Solsona, Spain; ${ }^{3}$ Departament de Biologia Animal, Universitat de Barcelona, Facultat de Biologia, \\ Avinguda Diagonal, 645, 08028-Barcelona, Spain; ${ }^{4}$ Corresponding author (email: Ignasi.Marco@uab.es)
}

ABSTRACT: Four little bustards (Tetrax tetrax) (one adult and three juvenile males), captured with leg nooses and fitted with a backpack radiotag, died after capture. The first bird was found after 16 days with its left foot caught in the harness and died after 1 day. The other birds showed symptoms of capture myopathy after release, such as the difficulty or inability to fly and/or walk. They died after 5, 6, and 8 days, respectively. At necropsy, muscles affected in all cases were those from the legs, and these were diffusely pale and dull, with a soft friable texture. Microscopically these muscles had multiple foci of myofiber fragmentation, loss of striation, and necrosis; a mononuclear cell infiltrate was observed in muscle from two birds. These findings suggest the little bustard is susceptible to capture myopathy and that caution should be exercised during its capture and handling.

Key words: Birds, capture myopathy, leg nooses, little bustard, radiotagging, Tetrax tetrax.

Capture myopathy, also known as exertional myopathy or exertional rhabdomyolysis, is a disease seen in animals during trapping, pursuit, capture, restraint, and transport. It is frequently reported in mammals, mainly in ungulates, but it has also been observed in birds (Williams and Thorne, 1996). Long-legged birds, like flamingoes, ostriches, and cranes, have been reported frequently to suffer capture myopathy (Bollinger et al., 1989). Additionally, this condition has been described in different species of waterfowl, gallinaceous birds, and raptors (Spraker et al., 1987; Domingo et al., 1991; Williams and Thorne, 1996; Höfle et al., 2004). Capture myopathy is characterized by damage to muscle tissues brought about by complex physiological changes that depend upon species and the circumstances of capture, physical exertion, and stress. However, hyperthermia and metabolic acidosis due to elevated levels of lactic acid from anaerobic glycolysis, as a response to intense muscular activity, are the central factors (Williams and Thorne, 1996).

The little bustard (Tetrax tetrax) is a near-threatened bird, about the size of a female pheasant, belonging to the Order Gruiformes, which breeds in open steppe and steppe-like landscapes. In the course of a radio-tracking study carried out in the Lleida plains $\left(41^{\circ} 33-46^{\prime} \mathrm{N}, 0-1^{\circ} 57-01^{\prime} \mathrm{E}\right)$ (Catalonia, NE Spain) in 2002 and 2004, four cases of capture myopathy (one adult and three juvenile males) after their capture, radiotagging, and release were reported. The birds were captured by leg nooses and fitted with backpack tags model TW3 (Biotrack, Dorset, UK). They were part of a larger group of 37 little bustards collected under the authority of permits from the Departament de Medi Ambient of the Catalonian government. The length of time that the birds were caught in the leg nooses before they were immobilized was less than 2 min. Measuring and marking were performed at the place of capture, and the total time of restraint was between 25 and $55 \mathrm{~min}$. They were also released at the place of capture. Two little bustards were frozen, and two were refrigerated prior to postmortem and histopathologic examinations. Tissues examined histologically included lung, heart, liver, spleen, kidney, and skeletal muscle from wings, pectoral, and femoral regions. They were fixed in $10 \%$ formalin, embedded in paraffin, sectioned at $5 \mu \mathrm{m}$, mounted on glass slides, and stained with hematoxylin and eosin.

All of the trapped birds appeared to be 
healthy at the time of capture. The first little bustard was found after 16 days with its left foot caught in the harness of the radiotag. It couldn't stand and was struggling to escape (flapping its wings) when discovered. The animal died 1 day after it arrived at the Wildlife Rehabilitation Centre of Vallcalent (Lleida). The other three little bustards showed difficulty or inability to fly and/or walk. In two birds, parts of the muscles from the right pectoral region, wing and leg, right lung, heart, gut, and spleen were removed by a bird of prey. However, it is not known if the birds were alive or not when they were predated.

At necropsy, the four little bustards had poor body condition. Muscles of the femoral region of both legs were diffusely pale, dull, and friable. In one bird, the iliotibialis cranialis of the left leg was also pale with streaked areas running parallel to the muscle bundle. Histopathologic examination of affected muscles from the legs showed extensive areas of muscular degeneration and necrosis. Myofiber changes included swelling, increased eosinophilia, multiple foci of fragmentation, loss of striations, and pyknotic and lost nuclei. In two birds, there were also intense areas of mononuclear cell invasion that replaced part of the muscular fibers.

The clinical findings and gross and histopathologic lesions described in the four little bustards were indicative of capture myopathy. Clinical signs of this condition in free-ranging birds are infrequently recorded after capture and marking operations (Spraker et al., 1987). Three of the little bustards in our study showed difficulty or inability to walk and/ or fly at the moment of release and remained near the place where they were released, until they died or were recaptured by hand. Two little bustards were found alive and sent to a Wildlife Rehabilitation Centre, but both died. Lesions of the little bustards were similar to those reported in wild red-legged partridges
(Alectoris rufa) (Höfle et al., 2004), but we did not observe hemorrhages in the affected muscles. Extensive areas of hemorrhage were also observed in lesser flamingoes (Phoenicopterus minor) and wild turkeys (Meleagridis gallopavo) after capture (Young, 1967; Spraker et al., 1987). Rocket nets used to capture wild turkeys and chasing and capturing flamingoes may have been more stressful for the animals compared to the leg nooses we used. However, other risk factors must be considered, such as species, sex, age, ambient temperature, pursuit time, restraint time, and transport duration (Williams and Thorne, 1996; Nicholson et al., 2000).

The histologic lesions of affected muscles of the birds in our study were mostly those previously reported for acute capture myopathy cases, such as swelling, multiple foci of fragmentation, loss of striation, and pyknosis of myofiber nuclei (Williams and Thorne, 1996). Although muscular hemorrhages and myocardial lesions have been frequently reported (Spraker et al., 1987; Tully et al., 1996), not all animals develop these lesions (Williams and Thorne, 1996). These lesions may be related to the severity of the disease and the time elapsed from muscular damage to death, which is influenced by the method of capture and other factors previously discussed. Increased cellularity was observed in two little bustards, but it was predominantly a mononuclear infiltrate, rather than the neutrophilic/heterophilic infiltrate previously described for capture myopathy in mammals and birds (Williams and Thorne, 1996). Renal lesions due to ischemia and myoglobin deposits are usually most pronounced after one week postexertion, but are not always present (Carpenter et al., 1991; Williams and Thorne, 1996) and were not observed in the little bustards.

Macroscopic and microscopic lesions were found only in the musculature of the legs of the affected little bustards, like 
in the sandhill crane and red-legged partridge (Carpenter et al., 1991; Höfle et al., 2004). Since all striated muscles can be affected, the distribution of lesions in the little bustards may reflect the nature of the exertion that induced the changes (Williams and Thorne, 1996). As legs have to be restrained in a flexed position, when the bustards struggle to escape, the leg muscles suffer intense physical exertion. The constant isotonic state may contribute to hindering blood flow and aggravating muscle hypoxia. It has been suggested that long-legged birds may be more susceptible to capture myopathy than are other birds (Carpenter et al., 1991). The little bustard can be considered a long-legged bird, since it belongs to the Order Gruiformes. To our knowledge, this is the first time that capture myopathy is described in the little bustard. However, it has been previously reported in other species of bustards, such as the houbara bustard (Chlamydotis undulata) and kori bustard (Ardeotis kori) (Bailey et al., 1996). These findings suggest that the little bustard is also susceptible to capture myopathy and that the family of bustards should be considered as a risk group. Furthermore, it can increase the probability of predation (Spraker et al., 1987), and this was probably the case in two of the little bustards studied here. Since treatment is extremely difficult, caution should be exercised during capture and handling, and every effort should be made to prevent the problem.

We are grateful to Berta Daussà, Yolanda Llop, and Rafel López (Centres de Recuperació de Fauna, Generalitat de Catalunya), Victor Garca (Ministerio de Medio Ambiente), Manolo Morales and Eladio Garcia (Universidad Autónoma de Madrid), Toni Ramis (Universitat Autònoma de Barcelona), Sergi Ricart, Pau Ferrer, Montse Raurell, Núria Pocino, Juan Bécares, and other collegues at the Ârea de Biodiversitat of the CTFC. This research has benefited from the financial support from Generalitat de Catalunya and REGSEGA, as well as from Ministerio de Educación y Ciencia (Spain). This is a contribution to project CGL200406147-C02-01/BOS.

\section{LITERATURE CITED}

Bailey, T. A., P. K. Nicholls, J. H. Samour, J. Naldo, U. Wernery, and J. C. Howlett. 1996. Postmortem findings in bustards in the United Arab Emirates. Avian Diseases 40: 296-305.

Bollinger, T., G. Wobeser, R. G. Clark, D. J. Nieman, and J. R. Smith. 1989. Concentration of creatine kinase and aspartate aminotransferase in the blood of wild mallards following capture by three methods for banding. Journal of Wildlife Diseases 25: 225-231.

Carpenter, J. W., N. J. Thomas, and S. Reeves. 1991. Capture myopathy in an endangered sandhill crane (Grus canadensis pulla). Journal of Zoo and Wildlife Medicine 22: 488-493.

Domingo, M., I. Marco-Sanchez, A. Marco-Valle, and M. Pumarola. 1991. Heart rupture and haemopericardium in captive-reared capercaille (Tetrao urogallus). Avian Pathology 20: 363366.

Höfle, U., J. Millan, C. Gortazar, F. J. Buenestado, I. Marco, and R. Villafuerte. 2004. Selfinjury and capture myopathy in net-captured juvenile red-legged partridge with niquelase radiotags. Wildlife Society Bulletin 32: $344-$ 350

Nicholson, D. S., R. L. Lochmiller, M. D. Stewart, R. E. Masters, and D. M. Leslie. 2000. Risk factors associated with capture-related death in Eastern wild turkey hens. Journal of Wildlife Diseases 36: 308-315.

Spraker, T. R., W. J. Adrian, and W. R. Lance. 1987. Capture myopathy in wild turkeys (Meleagridis gallopavo) following trapping, handling and transportation in Colorado. Journal of Wildlife Diseases 23: 447-453.

Tully, T. N., C. Hodgin, J. M. Morris, J. Williams, AND B. ZeBreZnik. 1996. Exertional myopathy in an emu (Dromaius novahollandiae). Journal of Avian Medicine and Surgery 10: 96-100.

Williams, E. S., and E. T. Thorne. 1996. Exertional myopathy (capture myopathy). In Noninfectious diseases of wildlife, A. Fairbrother, L. N. Locke and G. L. Hoff (eds.), 2nd Edition. Manson Publishing/Veterinary Press, London, pp. 181193.

Young, E. 1967. Leg paralysis in the great flamingo and lesser flamingo. International Zoo Yearbook 7: 226-227.

Received for publication 2 November 2005. 